\title{
Patient Report of Hearing in Neurofibromatosis Type 2
}

\author{
Recommendations for Clinical Trials
}

\begin{abstract}
Heather L. Thompson, PhD, CCC-SLP, Ann Blanton, PhD, CCC-SLP, Barbara Franklin, BS, Vanessa L. Merker, PhD, Kevin H. Franck, PhD, MBA, CCC-A, and D. Bradley Welling, MD, PhD, on behalf of the REiNS International Collaboration
\end{abstract}

Neurology ${ }^{\circledR}$ 2021;97:S64-S72. doi:10.1212/WNL.0000000000012424

\section{Abstract}

\section{Objective}

To systematically evaluate published patient-reported outcome measures for the assessment of hearing function and hearing-related quality of life (QoL) and recommend measures selected by the Response Evaluation in Neurofibromatosis and Schwannomatosis International Collaboration (REiNS) as endpoints for clinical trials in neurofibromatosis type 2 (NF2).

\section{Methods}

The REiNS Patient-Reported Outcomes Working Group systematically evaluated published patient-reported outcome measures of (1) hearing function and (2) hearing-related QoL for individuals with hearing loss of various etiologies using previously published REiNS rating procedures. Ten measures of hearing functioning and 11 measures of hearing-related QoL were reviewed. Measures were numerically scored and compared primarily on their participant characteristics (including participant age range and availability of normative data), item content, psychometric properties, and feasibility for use in clinical trials.

\section{Results}

The Self-Assessment of Communication and the Self-Assessment of CommunicationAdolescent were identified as most useful for adult and pediatric populations with NF2, respectively, for the measurement of both hearing function and hearing-related QoL. Measures were selected for their strengths in participant characteristics, item content, psychometric properties, and feasibility for use in clinical trials.

\section{Conclusions}

REiNS recommends the Self-Assessment of Communication adult and adolescent forms for the assessment of patient-reported hearing function and hearing-related QoL for NF2 clinical trials. Further work is needed to demonstrate the utility of these measures in evaluating pharmacologic or behavioral interventions.

\author{
Correspondence \\ Dr. Thompson \\ heather.thompson@ \\ csus.edu
}

From the Department of Communication Sciences and Disorders (H.L.T.), California State University, Sacramento; Department of Communication Disorders and Sciences (A.B.), SUNY Cortland, NY; REiNS Patient Representative for NF2 (B.F.); Department of Neurology and Cancer Center, Massachusetts General Hospital, Boston (V.L.M.); Center for Healthcare Organization and Implementation Research (CHOIR) (V.L.M.), Edith Nourse Rogers Memorial Veterans Hospital, Bedford; and Departments of Audiology (K.H.F.) and Otolaryngology and Head and Neck Surgery (D.B.W.), Massachusetts Eye and Ear Hospital and Massachusetts General Hospital, Boston.

Go to Neurology.org/N for full disclosures. Funding information and disclosures deemed relevant by the authors, if any, are provided at the end of the article.

REiNS International Collaboration coinvestigators are listed in the appendix 2 at the end of the article. 


\section{Glossary}

HEAR-QL-28 = Hearing Environments and Reflection on Quality of Life; NF2 = neurofibromatosis type 2; PRO = patientreported outcome; PRO-RATE = Patient-Reported Outcomes Rating Acceptance Tool for Endpoints; PROM = patientreported outcome measure; $\mathbf{Q o L}=$ quality of life; REiNS = Response Evaluation in Neurofibromatosis and Schwannomatosis; SAC $=$ Self-Assessment of Communication; SAC-A = Self-Assessment of Communication-Adolescent; SOAC $=$ Significant Other Assessment of Communication; SOAC-A = Significant Other Assessment of Communication-Adolescent; VS = vestibular schwannoma.

Neurofibromatosis type 2 (NF2) is a tumor-predisposing genetic disorder characterized by the proliferation of benign cranial nerve schwannomas, meningiomas, ependymomas, and cataracts. Bilateral vestibular schwannomas (VS), tumors of the eighth cranial nerve, occur in the majority of patients. ${ }^{1,2}$ Hearing loss and tinnitus are the common presenting symptoms, ${ }^{2,3}$ and usually have a gradual, slowly progressive course, but occur suddenly in approximately $10 \%$ of patients. ${ }^{4}$ Sensorineural hearing loss can occur secondary to tumor progression or as a consequence of surgery or radiation. Hearing loss can range from mild to profound in severity, and can cause significant difficulty during communication, especially when listening in background noise and when bilateral hearing is affected. Sound quality may be decreased proportionately more than would be expected for the degree of hearing loss of pure tones. Instrumentation such as hearing aids, ${ }^{5}$ cochlear implants, ${ }^{5,6}$ or auditory brainstem implants ${ }^{5,7}$ offer opportunities for improved hearing for patients with NF2. However, the progressive nature of the disease raises concern for cochlear nerve functionality and may reduce the utility of these instruments as long-term solutions for maintaining or restoring hearing in patients with NF2. ${ }^{8}$ Recently introduced pharmacologic interventions for reducing vestibular schwannoma size and morbidity in patients with NF2 show some success in maintaining or improving hearing, but are not effective for all patients. ${ }^{9,10}$

Auditory brainstem evoked responses, stapedial reflex recording, and electro-cochleography are used to obtain data regarding hearing mechanism functioning and sound processing. Pure tone audiometry and speech intelligibility assessments (such as speech discrimination or clarity scores) are carried out using standardized procedures to provide an assessment of the severity and nature of hearing loss. As comprehensive and routine as audiologic assessments and imaging studies may be, an evaluation of the patient's perception of how hearing loss affects hearing function and hearing-related quality of life (QoL) is frequently missing. ${ }^{11}$ Patient-reported outcome measures (PROMs) refer to "any report of the status of a patient's health condition that comes directly from the patient, without interpretation of the patient's response by a clinician or anyone else. ${ }^{12 \mathrm{p} 2 "}$ In the United States, the Food and Drug Administration requires clinical trials to include PROM data in addition to obtaining objective measures of patient functioning for medical product development. In NF2, data from audiologic assessments are correlated with but can differ from results of PROMs, suggesting that audiology results alone may not reflect the true degree of hearing benefit. ${ }^{13}$ PROMs are thus critical to demonstrating the success or failure of interventions aimed at reducing vestibular schwannoma size or slowing disease progression in NF2.

Studies conducted to evaluate relationships between QoL and (1) patient perception of NF2 severity, ${ }^{14}$ (2) vestibular schwannoma volume or hearing function, ${ }^{13}$ and (3) changes in hearing response with pharmacologic intervention ${ }^{9}$ have yielded variable results. The complex relationship of hearing function and QoL suggests the need for direct measurement of hearing-related QoL beyond standard audiologic measures to assess intervention benefit. For example, a prior NF2 clinical trial demonstrated improvements in QoL beyond those shown by measures of hearing function, suggesting that some aspects of hearing-related $\mathrm{QoL}$ are not captured by audiologic measurements. ${ }^{9}$ Therefore, further study is needed to delineate specifically how changes in hearing function relate to hearing-related $\mathrm{QoL}$ as perceived by patients. PROMs are a crucial component of NF2 clinical trials to fully ascertain clinical benefit. However, there is no consensus regarding optimal PROMs for use in NF2 clinical trials.

There are a number of challenges facing the use of PROMs for hearing in NF2. For a PROM to capture the progress of a disease or the results of a treatment, it must be able to provide a valid and reliable assessment of changes in an individual's communication status, such as alterations in hearing. Whereas the design of many clinical trials is focused on identifying measurable improvement, the loss of physiologic function experienced by patients with NF2 is typically progressive in nature. Continuous deterioration of hearing may take place during a clinical trial as a consequence of tumor progression and associated surgery, ${ }^{15,16}$ radiotherapy, ${ }^{7}$ or lack of a treatment effect. Given the nature of NF2, "no change" (tumor control) may be a positive outcome following successful treatment aimed at slowing disease progression. ${ }^{17}$ Recommended PROMs must not only be capable of capturing change when it occurs, but also exhibit reliability in identifying when there has been no decline. Many PROMs have a paucity of research regarding their development and lack information about reliability or validity in this context.

Patients with NF2 have heterogeneous hearing profiles and may use a variety of hearing devices such as hearing aids, 
cochlear implants, or auditory brainstem implants. An individual may have a device but not use it, use a device only during certain times of the day, or use the device only for specific activities. Clinicians and researchers must consider that because of variations in device usage, hearing function as measured by PROMs may fluctuate over recall periods for reasons unrelated to the progression or treatment of NF2. As many PROMs assessing hearing do not have manuals or clear instructions for patients regarding how listening contexts may influence what they hear for completing the PROM, data may be gathered inconsistently across administrations.

There is also the issue of determining what kinds of questions should be included in a PROM in the domain of hearing for patients with NF2. Several NF2 disease-specific PROMs have been developed; however, these measures often include many items asking about physical functioning (e.g., balance, facial weakness, mobility, or swallowing), ${ }^{18-20}$ and do not cover hearing functioning in depth. A number of PROMs have also been developed for use with older adults with hearing loss without NF2, ${ }^{21,22}$ but these measures include items that ask about how well an individual likes aspects of his or her hearing rehabilitation instrument, which may not be relevant to individuals with NF2 who do not utilize hearing aids or cochlear implants. Many PROMs that are used to assess hearing include items to assess tinnitus. Whereas tinnitus may be a concern for patients with NF, there is an immediate need for PROMs to assess hearing for patients with NF2 specifically.

In 2011, The Response Evaluation in Neurofibromatosis and Schwannomatosis (REiNS) International Collaboration was established with the purpose of achieving consensus for how to measure endpoints in NF clinical trials. ${ }^{23}$ The REiNS International Collaboration is composed of 8 working groups including (1) patient-reported outcomes, (2) functional outcomes, (3) imaging, (4) visual outcomes, (5) neurocognitive outcomes, (6) disease biomarkers, (7) cutaneous neurofibromas, and (8) patient representation. The PatientReported Outcomes Working Group was developed with the specific aim to identify PROMs relevant to NF clinical trials. ${ }^{24}$ As many clinical trials are completed as multicenter investigations, the harmonization of recommended measures is needed to enable study findings to be compared. Due to the heterogeneity of symptoms and variability in disease progression among individuals, measures need to be carefully selected with special attention to item content using measures that will capture changes over time. REiNS group work has developed a process to identify effective measurement scales and methods and prior publications have provided recommendations for PROMs assessing pain intensity, ${ }^{24,25}$ pain interference, $^{25}$ physical functioning, ${ }^{25}$ and most recently, generic and disease-specific QoL in NF (see Wolters et al., ${ }^{24,25}$ this supplement). To continue the progress made with the above recommendations, the objective of this article is to present current REiNS International Collaboration recommendations for PROMs used to evaluate hearing function and hearing-related QoL for NF2 clinical trials.

\section{Methods}

REiNS clinician-researchers, patient representatives, and other individuals in the NF2 clinical or research community were invited to participate in the REiNS Patient-Reported Outcomes (PRO) Communication Group. Among the individuals participating were patient representatives who could provide information to working group members about the feasibility of outcomes and the patient experience, a perspective that was extremely valuable to the project. Group work was initiated with web and telephone conference calls in September 2017 with the goals of (1) evaluating PROMs assessing the domain of hearing and (2) providing guidelines regarding the use of PROMs in NF2 clinical trials.

Target endpoint domains for hearing were researched, discussed, and 2 domains were identified as priority outcomes: (1) hearing function and (2) hearing-related QoL. Functional impairment PROMs included tools to assess an individual's perception of his or her ability to engage in activities of daily living. ${ }^{26}$ Hearing-related QoL included PROMs used to help describe an individual's perception of his or her ability to participate in physical or social activities and his or her degree of satisfaction in that participation in the context of a presenting health concern (hearing loss). ${ }^{27,28}$

A list of 35 PROMs addressing priority outcomes was compiled by the first author and distributed to group members for review. Measures developed for the sole purpose of evaluating tinnitus, amplification technology or devices, or hearing loss due to noise were excluded following group discussion due to the narrow focus of the measures and limitations in item content to adequately capture hearing concerns specific to patients with NF2, leaving 21 measures for full review. Due to the overlap with activities of the larger REiNS PRO Group, NF2 disease-specific measures were not included on the list (refer to the work of Wolters et al., ${ }^{24,25}$ this supplement, for more information).

Reviews of identified measures were completed using the Patient-Reported Outcomes Rating Acceptance Tool for Endpoints (PRO-RATE) form following procedures described previously. ${ }^{24}$ Each PROM was evaluated in 6 areas, including (1) patient characteristics (age range, published normative data, and measurement type including self-report or parent/teacher proxy form), (2) use in published studies (validation/normative data, descriptive study or clinical trial, and studies describing PROM use with populations with NF), (3) domains and item content (area assessed, clarity of item wording, and appropriateness for patients with NF), (4) scores available (raw, standard/transformed, domain, and total scores), (5) psychometric properties (reliability, validity, factor analysis, and sensitivity to change), and (6) feasibility for use in clinical trials (cost, length, ease of completion, languages available, and recall period), according to the definitions described by Wolters et al. ${ }^{24}$ Each PRO-RATE domain area was scored based on a review of published evidence 
and its applicability to NF2 clinical trials using a scale of 0 (limited/poor data) to 3 (solid data to support its use in NF clinical trials). Relevant publications for each measure were collected and reviews were completed independently by group members in advance of group discussions. Top-ranking scales in each domain were then re-reviewed to consider new publications and rating decisions were made through a sideby-side comparison with group discussion of the measures within the same meeting. ${ }^{25}$ The larger REiNS PRO group gave input and vetted final selections.

\section{Results}

We reviewed a total of 18 measures. Seven measures were reviewed for the domain of hearing function for adults and 4 were reviewed for children. Eight measures were reviewed for the domain of hearing-related QoL for adults and 4 were reviewed for children. Three of the measures were reviewed for both domains. ${ }^{11,29,30}$ As outcome measures are needed for clinical trials that include children and adults, priority was given to PROMs that were (1) self-report forms (as opposed to solely parent or significant other proxy report), (2) easy to understand, (3) strong in their psychometrics, (4) likely to show change in response to a variety of intervention types for individuals with NF2, and (4) parallel versions of assessments for children through to the adult years.

\section{Hearing Function Recommendation}

For the assessment of hearing functioning, the REiNS PRO Group recommended the Self-Assessment of Communication $\left(S A C^{11}\right)$ and the Self-Assessment of CommunicationAdolescent (SAC-A ${ }^{31}$ ). A summary of the review for the SAC/ $\mathrm{SAC}-\mathrm{A}$ is presented in table 1 and the measures are presented in eAppendices 1-4, links.lww.com/WNL/B457. A summary of measures reviewed is presented in table 2. The SAC is a short self-report measure developed according to recommendations made by the $\mathrm{WHO}^{11}$ and was designed to assess how hearing loss affects an individual's (1) perception of disability or activity limitation and (2) degree of communication or participation restriction. The SAC was designed for adults ages 25 and older and the SAC-A was designed for children and adolescents ages 11-19. Given the gap in ages between the child/adolescent and adult measures, the $\mathrm{PRO}$ group recommends the SAC for adults aged 20 years and older. Additional questionnaires are available for significant others (i.e., Significant Other Assessment of Communication [SOAC] and Significant Other Assessment of Communication-Adolescent [SOAC-A]). Significant others are defined as the spouse or best friend of the evaluated patient for the SOAC and the SOAC-A, respectively. ${ }^{11,31}$

Items for the SAC are divided into 3 sections asking about (1) hearing in various communication situations (e.g., Do you experience communication difficulties in situations when speaking with 1 other person?), (2) feelings about communication (e.g., Do you feel that any difficulty with your hearing limits or hampers your personal or social life?), and (3) other people's behavior (e.g., Do others suggest that you have a hearing problem?). ${ }^{11}$ Questions for the SAC-A included items from the SAC, modified by Elkayam and colleagues ${ }^{31,32}$ with permission from the original authors. Domains for the SAC-A include (1) hearing and understanding (e.g., Do you experience communication difficulties in situations when speaking with only 1 other person?), (2) feelings about communication (e.g., Does any problem or difficulty with your hearing loss upset you?), and (3) other people (e.g., Do other people ever notice that you have a hearing loss?). Respondents are required to complete the questionnaire according to how they communicate when a hearing aid is not in use.

The SAC and SAC-A are appropriate measures for clinical trials in NF2 with good reliability, face validity, ${ }^{31,32}$ and internal consistency (e.g., 0.95 and 0.79 for the domains of activity limitation and participation restriction, respectively). The measures are short, making the tool feasible for clinicians to administer for both clinical and research settings.

Relative weaknesses of the SAC include that at least 1 of the items may be difficult to understand (e.g., Do you experience communication difficulties when you are in an unfavorable listening environment?). The questionnaire does not consider spatial hearing, or "the ability to hear and process sounds from different locations." ${ }^{33 p 384}$ It is only available in English. Finally, no recall period is stated, which means the patient will most likely recall the most recent experience when completing the survey. This pattern of responding may be a problem in the context of a clinical trial if participants experience a great deal of fluctuation in their hearing over short periods of time.

\section{Hearing-Related QoL Recommendation}

The REiNS PRO Group also recommended the $S A C^{11}$ and the SAC-A ${ }^{31}$ for assessment of QoL related to hearing for adults and children, respectively. This measure was chosen because it has item content to assess hearing-related QoL (e.g., Do you feel that any difficulty with your hearing limits or hampers your social life? Does any problem or difficulty with your hearing upset you?) in addition to previously described item content on hearing functioning. The measures may be used with adolescents and adults aged 11+, whereas no other measure of hearing-related QoL was validated for both children and adults. The fact that this measure could be used to assess both hearing functioning and hearing-related QoL was also considered a strength for clinical trial feasibility, where reducing participant burden is key.

\section{Discussion}

PROMs assessing hearing function and hearing-related $\mathrm{QoL}$ are greatly needed to document the utility of interventions used in clinical trials in NF2. The purpose of this work was to utilize the previously described REiNS International Collaboration PRO Working Group protocol ${ }^{24,25}$ to evaluate published PROMs for the assessment of hearing function and 
Table 1 Review Criteria and Characteristics of the Self-Assessment of Communication (SAC) and the Self-Assessment of Communication-Adolescent (SAC-A)

\begin{tabular}{|c|c|}
\hline Criteria & Characteristics \\
\hline $\begin{array}{l}\text { Patient } \\
\text { characteristics }\end{array}$ & $\begin{array}{l}\text { - Patient and significant other form for children and adolescents } 11-19 \text { years }{ }^{31} \text { and for adults } 25-84 \text { years }{ }^{11} \\
\text { - Normative data for individuals aged } 12-18 \text { years with hearing loss }{ }^{31} \\
\text { - Normative data for individuals aged } 25-84 \text { years with and without hearing loss }{ }^{38}\end{array}$ \\
\hline $\begin{array}{l}\text { Domains/item } \\
\text { content }\end{array}$ & $\begin{array}{l}\text { - Domains assessed include hearing functioning and hearing-related quality of life } \\
\text { - } 10 \text {-item scale for adults and } 12 \text {-item scale for children/adolescents }{ }^{11,31} \text { to assess activity limitation and communication participation } \\
\text { restriction with items asking about the social or emotional effects of hearing loss } \\
\text { - Likert-type items rated on a } 1-5 \text { scale where } 1=\text { almost never (or never) and } 5=\text { practically always (or always) } \\
\text { - Total scores for the SAC range from } 10 \text { to } 60 \text {, where higher scores indicate greater difficulty }{ }^{39} \\
\text { - Good continuity of items between self-report and significant other forms }{ }^{11} \\
\text { - Parallel forms for children/adolescents and adults }\end{array}$ \\
\hline Psychometric data & $\begin{array}{l}\text { - Good test-retest reliability, with SAC paper and pencil }(1-3 \text { weeks })=0.80,{ }^{11} \text { SOAC paper and pencil }(1-3 \text { weeks })=0.90,{ }^{11} \text { SAC-A }(19 \\
\text { days apart; range } 14-28 \text { days })=0.76,{ }^{32} \text { SAC computerized version }(1-2 \text { weeks })=0.94,{ }^{38} \text { and SOAC computerized version }(1-2 \text { weeks })= \\
0.97^{38} \\
\text { - Changes of } 4-5 \text { points on the computerized version are consistent with changes of } 15 \% \text { and } 12 \% \text { on the SAC and SOAC, respectively, } \\
\text { and indicative of a critical difference }{ }^{38} \\
\text { - Good face validity for assessing hearing concerns in adolescents }{ }^{28,29} \\
\text { - Principal component analysis yielded } 1 \text { factor, with } 51.7 \% \text { of the variance explained }{ }^{39} \\
\text { - Internal consistency was good or acceptable }\left(\mathrm{SAC}=0.90^{39} ; \mathrm{SAC}-\mathrm{A}=0.76^{32}\right) \\
\text { - Strong correlations with the HHIE-S }\end{array}$ \\
\hline Feasibility & $\begin{array}{l}\text { - Free } \\
\text { - Can be completed quickly } \\
\text { - Computerized questionnaire includes } 8 \text { of } 10 \text { original items (computerized scoring available) } \\
\text { - Recommended that the SAC-A be completed in interview format to allow flexibility in administration } \\
\text { - SAC/SAC-A and SOAC/SOAC-A should be completed independently to reduce response bias }{ }^{31} \\
\text { - Available in English } \\
\text { - No recall period defined }\end{array}$ \\
\hline
\end{tabular}

Abbreviations: HHIE-S = Hearing Handicap Inventory for the Elderly-Screening; SOAC = Significant Other Assessment of Communication.

hearing-related QoL in NF2 clinical trials. Measures were reviewed and rated according to the PRO-RATE form and criteria described previously. ${ }^{24}$

To assess hearing function and hearing-related QoL, the REiNS International Collaboration recommends the SAC and the SAC-A as reliable and valid measures for clinical trials in NF2. The SAC and SAC-A are 10 or 12 items in length, respectively, and can be completed by patients aged 11 and older. Other report forms (SOAC/SOAC-A) with similar items to the self-report forms are also available if desired.

In reviewing available measures, the REiNS PRO Communication Group identified concerns in many available measures. Those that were not recommended had limited research to support their use, domains that were not appropriate for clinical trials in NF, or complex item wording or scoring. Although limited in terms of the languages available, the SAC/SAC-A exhibited relative strengths in the domains assessed and item content, psychometrics, availability of parallel measures across ages and respondents, and feasibility. We recommend use of the SAC/SAC-A for the assessment of hearing function and hearing-related $\mathrm{QoL}$ as an outcome measure for clinical trials in NF. It should be noted that these are preliminary recommendations based upon current studies and available literature. Clinicians and researchers are encouraged to evaluate recommended outcomes and select measures depending upon specific trial design and participant inclusion/exclusion criteria.
It is recommended that researchers conducting NF2 clinical trials aimed at improving or stabilizing hearing functioning include these PROMs in addition to an audiologic evaluation following REiNS International Collaboration Functional Outcomes Working Group recommendations. ${ }^{34}$ Researchers administering the SAC and SAC-A are encouraged to write additional PROM administration instructions into their clinical trial protocols to ensure consistency of responses within and among participants. Protocols should record listening conditions to best account for and accommodate daily fluctuations in hearing. For participants utilizing amplification, researchers may wish to give instructions for participants to complete the SAC twice: once while reflecting on hearing without a device and a second time while reflecting on hearing with a device. Researchers may also wish to ask additional questions to gather information regarding current hearing device use, adjunct hearing technologies utilized, participant age, hearing status (e.g., unilateral or bilateral hearing loss), balance, and vision.

Clinical trials could consider evaluating changes in SAC/SACA scores from pre to post using interventions such as hearing instrumentation (auditory brainstem implants or cochlear implants), pharmacologic regimens (e.g., bevacizumab), or behavioral interventions (e.g., aural rehabilitation or psychological support). PROMs can be administered at different time points across a clinical trial with the research team documenting the type of device utilized. Future studies should seek to examine 
Table 2 Summary of Identified Strengths and Limitations of Measures Used to Assess Hearing Functioning and HearingRelated Quality of Life

\begin{tabular}{|c|c|c|c|}
\hline Measure and domain area & $\begin{array}{l}\text { Report } \\
\text { format; age } \\
\text { range, } y \text {; } \\
\text { number of } \\
\text { items }\end{array}$ & Strengths for use in NF clinical trials & Limitations for use in NF clinical trials \\
\hline Auditory Behavior in Everyday Life ${ }^{40} ; \mathrm{HF}$ & PR; 4-14; 26 & $\begin{array}{l}\text { DA: parent perceptions of hearing function in } \\
\text { daily living; easy administration; multiple } \\
\text { languages; free }\end{array}$ & $\begin{array}{l}\text { PD weak; limited studies only validated } \\
\text { measure; no research in NF }\end{array}$ \\
\hline $\begin{array}{l}\text { Amsterdam Inventory for Auditory } \\
\text { Disability-Modified }{ }^{41} ; \mathrm{HF}\end{array}$ & SR; 17-65; 28 & $\begin{array}{l}\text { DA: sound detection, discrimination, } \\
\text { localization, intelligibility in noise and quiet; } \\
\text { good PD; easy administration; multiple } \\
\text { languages; free }\end{array}$ & $\begin{array}{l}\text { Limited published studies; no research in } \\
\text { NF; complex wording; no child normative } \\
\text { data; difficult item response format }\end{array}$ \\
\hline $\begin{array}{l}\text { Attitudes Toward Loss of Hearing } \\
\text { Questionnaire }{ }^{22} ; \text { HRQoL }\end{array}$ & SR; 20-86; 22 & $\begin{array}{l}\text { DA: effect of hearing loss, HA stigma, } \\
\text { acceptance/adjustment, awareness; excellent } \\
\text { PD; easy administration; multiple languages; } \\
\text { free }\end{array}$ & $\begin{array}{l}\text { Limited research; no research in NF; } \\
\text { focused on HA; scoring not clear }\end{array}$ \\
\hline $\begin{array}{l}\text { Classroom Participation } \\
\text { Questionnaire }{ }^{43} ; \mathrm{HRQ} \mathrm{LL}\end{array}$ & $\begin{array}{l}\text { SR, TR; } \\
\text { children } \\
\text { grades 2-8; } 28\end{array}$ & $\begin{array}{l}\text { Good PD; easy administration; short form } \\
\text { available; normed on deaf and hard-of-hearing } \\
\text { students; free }\end{array}$ & $\begin{array}{l}\text { DA: communication between students/ } \\
\text { teachers/peers; SR of classroom; limited to } \\
\text { academic environment; English only; no } \\
\text { research in NF }\end{array}$ \\
\hline $\begin{array}{l}\text { Client-Oriented Scale of } \\
\text { Improvement }^{30} ; \text { HF/HRQoL }\end{array}$ & $\begin{array}{l}\text { SR; } 67-75 ; 16 \\
\text { categories }\end{array}$ & $\begin{array}{l}\text { DA: perception of rehab benefits, decreased } \\
\text { disability, emotion; trials over time; multiple } \\
\text { studies; good PD; child version available; easy } \\
\text { administration; free }\end{array}$ & $\begin{array}{l}\text { Scores difficult to compare across } \\
\text { individuals in the context of a clinical trial; } \\
\text { English only; no research in NF }\end{array}$ \\
\hline $\begin{array}{l}\text { Communication Profile for the Hearing } \\
\text { Impaired (CPHI) }{ }^{44} \text { and Screening Test for } \\
\text { Hearing Problems (STHP); HRQ }\end{array}$ & $\begin{array}{l}\text { SR; 20-70; } \\
\text { CPHI 145, } \\
\text { STHP } 20\end{array}$ & $\begin{array}{l}\text { DA: performance, environment, strategies, } \\
\text { adjustment; trials over time; excellent PD; } \\
\text { short form available; multiple languages; free }\end{array}$ & $\begin{array}{l}\text { Pilot data from active and retired military } \\
\text { (13 female); HA data; no research in NF; no } \\
\text { recall period; CPHI long to complete with } \\
\text { many instructions }\end{array}$ \\
\hline
\end{tabular}

Everyday Listening Questionnaire $\mathbf{2}^{45}$; HF SR; $23-78 ; 6$

DA: speech understanding in multiple environments, enjoyment of music; clinical trial use; easy administration; multiple languages; free

No PD; adults only with cochlear implants reported; no research in NF

\begin{tabular}{lcl}
\hline $\begin{array}{l}\text { Glasgow Children's Benefit Inventory }{ }^{\mathbf{4 6} ;} \text { HRQoL } \\
\text { PR; 1-19; } 24\end{array}$ & $\begin{array}{l}\text { DA: physical, social, emotional, cognitive, education/ } \\
\text { development, functional, general health; good PD; } \\
\text { easy administration; multiple languages }\end{array}$ \\
\hline Hearing Beliefs Questionnaire ${ }^{21}$; HRQoL & SR; 18-90; 26 & $\begin{array}{l}\text { DA: social, emotional, cognitive; good PD; easy } \\
\text { administration; free }\end{array}$
\end{tabular}

Retrospective data only; focused on surgery outcomes; not specifically related to hearing concerns; difficult to score; no research in NF $\begin{array}{ll}\text { social, emotional, cognitive; good PD; easy } & \text { Clinical trials by } 1 \text { researcher; significantly } \\ \text { older male veterans; no research in NF; }\end{array}$ hearing aid assessment; English only

\begin{tabular}{lll}
\hline $\begin{array}{l}\text { Hearing Environments and Reflection on } \\
\text { Quality of Life Measurement for } \\
\text { Children }\end{array}$;7 HRQoL & SR-18; 26 & $\begin{array}{l}\text { DA: physical, social, emotional, cognitive, } \\
\text { listening environments; good PD; easy } \\
\text { administration }\end{array}$ \\
\hline $\begin{array}{l}\text { Hearing Handicap Inventory for the } \\
\text { Elderly-Screening }\end{array}$ & SR; 13-84; 25 & $\begin{array}{l}\text { DA: social, emotional, perceived degree of } \\
\text { concern; good PD; many etiology types } \\
\text { studied; easy administration; multiple } \\
\text { languages; free }\end{array}$
\end{tabular}

Only 2 studies (validation); adolescents only with hearing loss; no research in NF; licensing/cost; English only

DA not appropriate for clinical trials in NF; focused on older adult population; no research in NF; different items across versions of the scale

\begin{tabular}{|c|c|c|}
\hline $\begin{array}{l}\text { Hearing Measurement Scale }{ }^{29} \text {; } \\
\text { HF/HRQoL }\end{array}$ & $\mathrm{SR} ; 40+; 42$ & $\begin{array}{l}\text { DA: speech/nonspeech hearing, localization, } \\
\text { emotion, recruitment, tinnitus, perception of } \\
\text { hearing; appropriate for NF related to hearing } \\
\text { loss and perception; good PD; multiple } \\
\text { languages; free; short version available }\end{array}$ \\
\hline
\end{tabular}

\begin{tabular}{lll}
\hline Listening Inventory For & SR/TR; 6+, 8+; & Easy administration; shorter 7-item version \\
Education-Revised $^{47} ;$ HF & 15 (pre)/6 (post) & available; free
\end{tabular}

Mostly men with noise-induced hearing loss; limited research; no research in NF; different response formats across questions; complex wording

\author{
Education-Revised ${ }^{47}$; HF
}

The Penn Acoustic Neuroma

Quality-of-Life Scale ${ }^{48}$; HRQoL
SR; 18-88; 26 DA: hearing, balance, face, anxiety, energy, pain, general health; very good $P D$; data from patients with non-NF2 acoustic neuromas; multiple languages; free

\footnotetext{
Self-Assessment of Communication (SAC) SAC: SR, SO;

11 and Self-Assessment of 25-84; 10;

Communication-Adolescent (SAC-A) ${ }^{31}$; Significant Other Assessment of Communication ${ }^{11,31}$; HF/HRQ

DA: include disability/activity limitation, appropriate for NF; wide age range with SAC-A: SR, SO; parallel forms from child to adult; multiple $11-19 ; 12 \quad$ studies including clinical trials; good PD; minimal clinically important difference scores available; easy administration; free
}

DA not appropriate for clinical trials in NF; no research in NF; limited PD; children only; English only

DA not focused specifically on hearing; score obtained is for the total instrument, not by item

SAC-A items thought to mask "emotions and attitudes" revealed through dialogue; no research in NF; English only 
Table 2 Summary of Identified Strengths and Limitations of Measures Used to Assess Hearing Functioning and HearingRelated Quality of Life (continued)

\begin{tabular}{|c|c|c|c|}
\hline Measure and domain area & $\begin{array}{l}\text { Report } \\
\text { format; age } \\
\text { range, } y \text {; } \\
\text { number of } \\
\text { items }\end{array}$ & Strengths for use in NF clinical trials & Limitations for use in NF clinical trials \\
\hline Spatial Hearing Questionnaire ${ }^{49} ; \mathrm{HF}$ & SR; 18-61; 24 & $\begin{array}{l}\text { Excellent PD; easy administration; multiple } \\
\text { languages }\end{array}$ & $\begin{array}{l}\text { DA: specifically examines spatial hearing; } \\
\text { cochlear implant studies only; no research } \\
\text { in NF }\end{array}$ \\
\hline $\begin{array}{l}\text { Speech, Spatial and Qualities } \\
\text { of Hearing Scale }{ }^{50} ; \mathrm{HF}\end{array}$ & $\begin{array}{l}\text { PR, TR; 5+; SR; } \\
11+; 49\end{array}$ & $\begin{array}{l}\text { DA: speech hearing, spatial hearing; } \\
\text { appropriate for NF; good PD; many studies } \\
\text { including clinical trials; includes research in NF; } \\
\text { multiple languages }\end{array}$ & $\begin{array}{l}\text { Long; recommended child form } \\
\text { administered via interview; nonparallel } \\
\text { items in adult/child versions }\end{array}$ \\
\hline
\end{tabular}

Abbreviations: $\mathrm{DA}=$ domains assessed; $\mathrm{HA}=$ hearing aids; $\mathrm{HF}=$ hearing functioning; $\mathrm{HRQ} \mathrm{L}$ = hearing-related quality of life; $\mathrm{NF}=$ neurofibromatosis; $\mathrm{PD}=$ psychometric data; $P R=$ parent-report; $S O=$ significant other; $S R=$ self-report; TR = teacher-report.

the utility of PROMs for behavioral or pharmacologic trials in NF2. There is a need for research aimed at (1) developing and validating tools for hearing-related $\mathrm{QoL}^{35}$ for patients with and without NF2 and (2) evaluating the utility of audiologic rehabilitation for improving hearing outcomes for patients with NF2. Finally, given that the SAC and SAC-A are only available in English, it is recommended that future research focus on the acquisition of normative data for versions of the SAC, SAC-A, and significant other forms in other languages.

Results of this work have identified a need for normative data from PROMs used to assess hearing function and hearingrelated QoL for children and adults with NF2. NF2-specific normative data are needed since PROMs to assess hearing are frequently normed on populations of older adults, including veterans, without $\mathrm{NF} 2 .^{22,36}$ Older adults may have very different etiologies of hearing loss and profiles than individuals with NF2, warranting further study in this area.

Continued work is needed to evaluate PROMs related to hearing function and hearing-related QoL for young children, as there is insufficient evidence for use of the SAC-A with children under the age of 11 . It is important to consider that if a child with NF2 exhibits symptoms relatable to VS, the child likely has a more severe and rapidly progressive form of the disorder, which may affect hearing-related QoL. As children are enrolled in NF2 clinical trials, information regarding the psychometric properties of these measures for use with children is needed. It should be noted that the Hearing Environments and Reflection on Quality of Life (HEAR-QL-28 ${ }^{37}$ ) was considered as an assessment of hearing-related QoL for younger children that extends down to age 7 . This measure is composed of 26 clearly worded items that ask about perceived involvement in activities, feelings, and hearing in different environments. Whereas the HEAR-QL-28 was not a primary recommendation given that it has no parallel measure for adults and may not be feasible due to costs, clinicianresearchers may wish to consider the HEAR-QL-28 if conducting a pediatric-only clinical trial.
The REiNS PRO Communication Group is continuing to work to identify appropriate baseline and end point PROMs for clinical trials in neurofibromatosis. Directions for future REiNS PRO Communication Group work will be to identify valid and reliable PROMs for the assessment of all patients, including those with concerns in speech, language, or hearing, to ensure that client-caregiver perspectives can be accurately understood throughout clinical trials across the lifespan. Researchers and clinicians are encouraged to collaborate with patient representatives during pharmacologic and behavioral clinical trials and subsequently use PROM data to determine clinically significant changes in outcomes deemed most important to patients.

\section{Acknowledgment}

The authors thank the following members of the REiNS International Collaboration PRO Group for their input into the side-by-side review of hearing measures: Pam Wolters, Andrea Baldwin, Carolina Barnett, Staci Martin, Kimberley Koetsier, Tena Rosser, and Elizabeth Schorry; Jane Grabowski for her input on a later draft of the manuscript; and the Children's Tumor Foundation for their support of the REiNS International Collaboration.

\section{Study Funding}

This research is supported by the Intramural Research Program of the NIH, National Cancer Institute; the Department of Veterans Affairs Office of Academic Affiliations Advanced Fellowship Program in Health Services Research; the Center for Healthcare Organization and Implementation Research (CHOIR); and the Edith Nourse Rogers Memorial Veterans Hospital. The views expressed in this article are those of the authors and do not necessarily reflect the position or policy of the Department of Veterans Affairs or the US government. This study is not industry sponsored.

\section{Disclosure}

The authors report no disclosures. Go to Neurology.org/N for full disclosures. 


\section{Publication History}

Received by Neurology October 9, 2020. Accepted in final form May 3, 2021.

Appendix 1 Authors

\begin{tabular}{lll}
\hline Name & Location & Contribution \\
\hline $\begin{array}{l}\text { Heather L. } \\
\text { Thompson, } \\
\text { PhD, CCC-SLP }\end{array}$ & $\begin{array}{l}\text { California State University, } \\
\text { Sacramento }\end{array}$ & $\begin{array}{l}\text { Design and } \\
\text { conceptualization of the } \\
\text { study, data collection, } \\
\text { statistical analysis and } \\
\text { interpretation of the data, } \\
\text { drafting and revising the } \\
\text { manuscript }\end{array}$ \\
& &
\end{tabular}

Ann Blanton, SUNY Cortland, NY PhD, CCC-SLP

Study concept, collection and interpretation of the data, drafting and revising the manuscript

Barbara REiNS International

Franklin, BS Collaboration patient representative

Study concept, collection and interpretation of the data, drafting and revising the manuscript

Vanessa L. Center for Healthcare

Merker, PhD Organization and Implementation Research (CHOIR), Edith Nourse Rogers Memorial Veterans Hospital, Bedford, MA

Kevin $\mathbf{H}$. Harvard Department of Franck, PhD, Otolaryngology Head and MBA, CCC-A Neck Surgery, Massachusetts Eye and Ear and Massachusetts General Hospital, Boston

\begin{tabular}{|c|c|c|}
\hline $\begin{array}{l}\text { D. Bradley } \\
\text { Welling, MD, } \\
\text { PhD }\end{array}$ & $\begin{array}{l}\text { Harvard Department of } \\
\text { Otolaryngology Head and } \\
\text { Neck Surgery, } \\
\text { Massachusetts Eye and Ear } \\
\text { and Massachusetts General } \\
\text { Hospital, Boston }\end{array}$ & $\begin{array}{l}\text { Study concept, collection } \\
\text { and interpretation of the } \\
\text { data, drafting and revising } \\
\text { the manuscript }\end{array}$ \\
\hline
\end{tabular}

\section{References}

1. Iwatate $\mathrm{K}$, Yokoo T, Iwatate E, et al. Population characteristics and progressive disability in neurofibromatosis type 2. World Neurosurg. 2017;106(XX):653-660.

2. Parry DM, Eldridge R, Kaiser-Kupfer MI, Bouzas EA, Pikus A, Patronas N. Neurofibromatosis 2 (NF2): clinical characteristics of 63 affected individuals and clinical evidence for heterogeneity. Am J Med Genet. 1994;52(4):450-461.

3. Kentala E, Pyykkö I. Clinical picture of vestibular schwannoma. Auris Nasus Larynx. 2001;28(1):15-22

4. Moffat DA, Baguley DM, von Blumenthal H, Irving RM, Hardy DG. Sudden deafness in vestibular schwannoma. J Laryngol Otol. 1994;108(2):116-119.

5. Jia H, El Sayed MME, Smail M, et al. Neurofibromatosis type 2: hearing preservation and rehabilitation. Neurochirurgie. 2018;64(5):348-354.

6. Jia H, Nguyen Y, Hochet B, et al. NF2-related intravestibular schwannomas: longterm outcomes of cochlear implantation. Otol Neurotol. 2020;41(1):94-99.

7. Lloyd SKW, King AT, Rutherford SA, et al. Hearing optimisation in neurofibromatosis type 2: a systematic review. Clin Otolaryngol. 2017;42(6):1329-1337.

8. West N, Sass H, Caye-Thomasen P. Sporadic and NF2-associated vestibular schwannoma surgery and simultaneous cochlear implantation: a comparative systematic review. Eur Arch Otorhinolaryngol. 2019;277(2):333-342.

9. Plotkin SR, Duda DG, Muzikansky A, et al. Multicenter, prospective, phase II and biomarker study of high-dose bevacizumab as induction therapy in patients with neurofibromatosis type 2 and progressive vestibular schwannoma. J Clin Oncol. 2019; 37(35):3446-3454.

10. Gugel I, Kluwe L, Zipfel J, et al. Minimal effect of bevacizumab treatment on residual vestibular schwannomas after partial resection in young neurofibromatosis type 2 patients. Cancers. 2019;11(12):1862.

11. Schow RL, Nerbonne MA. Communication screening profile: use with elderly clients. Ear Hear. 1982;3(3):135-147.
12. Food and Drug Administration. Patient-Reported Outcome Measures: Use in Medical Product Development to Support Labeling Claims Guidance for Industry. Available at: fda. gov/regulatory-information/search-fda-guidance-documents/patient-reported-outcome-measures-use-medical-product-development-support-labeling-claims.

13. Merker V, Bergner AL, Vranceanu AM, Muzikansky A, Slattery W, Plotkin SR. Healthrelated quality of life of individuals with neurofibromatosis type 2: results from the NF2 natural history study. Otol Neurotol. 2016;37(5):574-579.

14. Neary WJ, Hillier VF, Flute T, Stephens SD, Ramsden RT, Evans DG. The relationship between patients' perception of the effects of neurofibromatosis type 2 and the domains of the Short Form-36. Clin Otolaryngol. 2010;35(4):291-299.

15. Gugel I, Grimm F, Liebsch M, et al. Impact of surgery on long-term results of hearing in neurofibromatosis type-2 associated vestibular schwannomas. Cancers. 2019;11(9):1376.

16. Bonne NX, Risoud M, Hoa M, et al. Hearing response following internal auditory canal decompression in neurofibromatosis type 2. Neurosurgery. 2019;85(3):E560-e567.

17. North HJD, Lloyd SKW. Hearing rehabilitation in neurofibromatosis type 2. Adv Otorhinolaryngol. 2018;81:93-104.

18. Cosetti MK, Golfinos JG, Roland JT. Quality of life ( $\mathrm{OoL}$ ) assessment in patients with neurofibromatosis type 2 (NF2). Otolaryngol Head Neck Surg. 2015;153(4): 599-605.

19. Hornigold RE, Golding JF, Leschziner G, et al. The NFTI-QOL: a disease-specific quality of life questionnaire for neurofibromatosis 2. J Neurol Surg B. 2012;73(2):104-111.

20. Neary WJ, Hillier VF, Flute T, Stephens D, Ramsden RT, Evans DG. Use of a closed set questionnaire to measure primary and secondary effects of neurofibromatosis type 2. J Laryngol Otol. 2010;124(7):720-728.

21. Saunders GH, Frederick MT, Silverman S, Papesh M. Application of the health belief model: development of the Hearing Beliefs Questionnaire (HBQ) and its associations with hearing health behaviors. Int J Audiol. 2013;52(8):558-567.

22. Cox RM, Alexander GC. Measuring satisfaction with amplification in daily life: the SADL scale. Ear Hear. 1999;20(4):306

23. Plotkin SR, Blakeley JO, Dombi E, et al. Achieving consensus for clinical trials: the REiNS International Collaboration. Neurology. 2013;81(21 suppl 1):S1-S5.

24. Wolters PL, Martin S, Merker VL, et al. Patient-reported outcomes in neurofibromatosis and schwannomatosis clinical trials. Neurology. 2013;81(21 suppl 1): S6-S14.

25. Wolters PL, Martin S, Merker VL, et al. Patient-reported outcomes of pain and physical functioning in neurofibromatosis clinical trials. Neurology. 2016;87(7 suppl 1):S4-S12.

26. Stein REK, Jessop DJ. Functional Status II: a measure of health status. Med Care. 1990; 28(11):1041-1055.

27. Palermo TM, Long AC, Lewandowski AS, Drotar D, Quittner AL, Walker LS Evidence-based assessment of health-related quality of life and functional impairment in pediatric psychology. J Pediatr Psychol. 2008;33(9):983-988.

28. Naughton MJ, Shumaker SA. The case for domains of function in quality of life assessment. Qual Life Res. 2003;12(suppl 1):73-80.

29. Noble WG, Atherley GRC. The Hearing Measurement Scale: a questionnaire for the assessment of auditory disability. J Auditory Res. 1970;10:229-250.

30. Dillon A, Ginis J. Client Oriented Scale of Improvement (COSI) and its relationship to several other measures of benefit and satisfaction provided by hearing aids. J Am Acad Audiol. 1997;8(1):27-43.

31. Elkayam J, English K. Counseling adolescents with hearing loss with the use of self-assessment/significant other questionnaires. J Am Acad Audiol. 2003;14(9): 485-499.

32. Wright K, English K, Elkayam J. Reliability of the Self-Assessment of Communication-Adolescent (SAC-A). J Educ Audiol. 2010;16:4-10.

33. Zhang J, Tyler R, Ji H, et al. Speech, Spatial and Qualities of Hearing Scale (SSQ) and Spatial Hearing Questionnaire (SHQ) changes over time in adults with simultaneous cochlear implants. Am J Audiol. 2015;24(3):384-397.

34. Plotkin SR, Ardern-Holmes SL, Barker FG, et al; for the REiNS International Collaboration. Hearing and facial function outcomes for neurofibromatosis 2 clinical trials. Neurology. 2013;81(21 suppl 1):S25-S32.

35. Punch JL, Hitt R, Smith SW. Hearing loss and quality of life. J Commun Disord. 2019; 78:33-45.

36. Ventry IM, Weinstein BE. The Hearing Handicap Inventory for the elderly: a new tool. Ear Hear. 1982;3(3):128-134.

37. Umansky AM, Jeffe DB, Lieu JEC. The HEAR-QL: quality of life questionnaire for children with hearing loss. J Am Acad Audiol. 2011;22(10):644-653.

38. Hodes M, Schow RL, Brockett J. New support for hearing aid outcome measures: the computerized SAC and SOAC. Hear Rev. 2009;16(12):26-36.

39. Hickson L, Worrall L, Scarinci N. A randomized controlled trial evaluating the active communication education program for older people with hearing impairment. Ear Hear. 2007;28(2):212-230.

40. Purdy SC, Farrington DR, Moran CA, Chard LL, Hodgson SA. A parental questionnaire to evaluate children's auditory behavior in everyday life (ABEL). Am J Audiol. 2002;11(2):72-82

41. Meijer AG, Wit HP, TenVergert EM, Albers FW, Muller Kobold JE. Reliability and validity of the (modified) Amsterdam inventory for auditory disability and handicap. Int J Audiol. 2003;42(4):220-226.

42. Saunders G, Cienkowski KM. Refinement and psychometric evaluation of the attitudes toward loss of hearing questionnaire. Ear Hear. 1996;17(6):505-519.

43. Antia SD, Sabers DL, Stinson MS. Validity and reliability of the classroom participation questionnaire with deaf and hard of hearing students in public schools. J Deaf Stud Deaf Educ. 2007;12(2):158-171.

44. Demorest ME, Erdman SA. Development of the communication profile for the hearing impaired. J Speech Hear Disord. 1987;52(2):129-143. 
45. Goldring J, Gault A. Everyday listening questionnaire: a new evaluation tool for adult cochlear implant users. Adv Bionics Auditory Res Bull. 2007;15(1):180-181.

46. Kubba H, Swan IR, Gatehouse S. The Glasgow Children's Benefit Inventory: a new instrument for assessing health-related benefit after an intervention. Ann Otol Rhinol Laryngol. 2004;113(12):980-986.

47. Anderson K, Smaldino JJ, Spangler C. The Listening Inventories for Education-Revised. Available at: successforkidswithhearingloss.com/tests
48. Shaffer BT, Cohen MS, Bigelow DC, Ruckenstein MJ. Validation of a disease-specific quality-of-life instrument for acoustic neuroma: the Penn Acoustic Neuroma Qualityof-Life Scale. Laryngoscope. 2010;120(8):1646-1654.

49. Tyler RS, Perreau AE, Ji H. Validation of the spatial hearing questionnaires. Ear Hear. 2009;19(6):466-474.

50. Gatehouse S, Noble W. The Speech, Spatial and Qualities of Hearing Scale (SSQ). Int J Audiol. 2004;43(2):85-99. 


\section{Neurology}

\section{Patient Report of Hearing in Neurofibromatosis Type 2: Recommendations for Clinical Trials}

Heather L. Thompson, Ann Blanton, Barbara Franklin, et al.

Neurology 2021;97;S64-S72 Published Online before print July 6, 2021

DOI 10.1212/WNL.0000000000012424

This information is current as of July 6, 2021

\section{Updated Information \&} Services

References

Citations

Subspecialty Collections

Permissions \& Licensing

Reprints including high resolution figures, can be found at: http://n.neurology.org/content/97/7_Supplement_1/S64.full

This article cites 48 articles, 4 of which you can access for free at: http://n.neurology.org/content/97/7_Supplement_1/S64.full\#ref-list-1

This article has been cited by 1 HighWire-hosted articles: http://n.neurology.org/content/97/7_Supplement_1/S64.full\#\#otherartic les

This article, along with others on similar topics, appears in the following collection(s):

Clinical trials Methodology/study design

http://n.neurology.org/cgi/collection/clinical_trials_methodology_study design

Neurofibromatosis

http://n.neurology.org/cgi/collection/neurofibromatosis

Information about reproducing this article in parts (figures,tables) or in its entirety can be found online at:

http://www.neurology.org/about/about_the_journal\#permissions

Information about ordering reprints can be found online:

http://n.neurology.org/subscribers/advertise

Neurology ${ }^{\circledR}$ is the official journal of the American Academy of Neurology. Published continuously since 1951, it is now a weekly with 48 issues per year. Copyright (C 2021 American Academy of Neurology. All rights reserved. Print ISSN: 0028-3878. Online ISSN: 1526-632X.

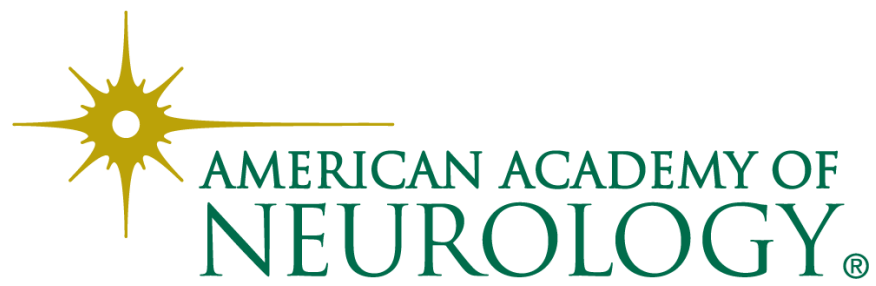

